\title{
Effect of Heat Treatment and Reinforcements on the Mechanical Properties of Closed Cell Al-Cu Alloy Foam
}

\author{
Soheil Abdolkarimzadeha ${ }^{1}$, Nima Movahedia ${ }^{1}$ *, Seyyed Mohammad Hossein Mirbagheri ${ }^{2}$, \\ Omid Mirzaee \\ 1 Department of Metallurgy and Materials Engineering, Faculty of Engineering, Semnan University, \\ Semnan, Iran \\ 2. Department of Mining and Metallurgical Engineering, Amirkabir University of Technology, \\ Tehran, Iran \\ *corresponding author, nima.movahedi@sgpco.com
}

\begin{abstract}
Keywords: Closed cell aluminum foam, mechanical properties, heat treatment, Reinforcement.

Abstract. In this research work, closed aluminum foams produced by powder metallurgy method, the aging heat treatment was performed on samples to evaluate the effect of copper as an alloying element and TiB2 as reinforcement on the mechanical properties of aluminum foams. The results indicated that, in this alloy foam, TiB2 particles play minor role on the mechanical properties, while the aging heat treatment enhanced the mechanical properties of the foam samples dramatically. In addition, the size of age hardening precipitates was smaller than the external reinforcement.
\end{abstract}

\section{Introduction}

Aluminum foam due to their unique properties has become popular during last decades. The high strength to weight ration made this material as an appropriate candidate for automobile application. The high energy absorption ability of its cellular structure absorbs the huge amount of energy during accident and provides a safety condition for passengers. Closed cell aluminum foams produced by melting and powder metallurgy method. In both routes the distributed foaming agent within the aluminum matrix produce the foam structure with closed cell morphology [1].Different types of reinforcements have been added to the aluminum matrix prior foaming step In order to increase the mechanical properties of closed cell aluminum foams [3-4]. $\mathrm{TiB}_{2}$ is one of the additives that has been recently used for this purpose [5]. In spite of improving the mechanical properties of aluminum foams, there are some points that should be taken into account during using these additives. For instance, low wettability of reinforcement by matrix, nonhomogeneous distribution within metal matrix and brittleness of composite are some usual problems that will appear by using 
ceramic particles .Therefore, the goal of this research is to compare the effect of heat treatment and $\mathrm{TiB} 2$ on the mechanical behavior of $\mathrm{Al}-4.5 \mathrm{wt} \% \mathrm{Cu}$ alloy foams.

\section{Materials and Methods}

Closed cell aluminum foam samples produced by powder metallurgy route. For this purpose, Al$4.5 \mathrm{wt} \% \mathrm{Cu}$ alloy was prepared by mixing aluminum powder (99\%) with 63 micron particle size and $4.5 \mathrm{wt} \%$ of copper (99\% purity and 45 micron size) as the matrix. Two groups of samples prepared. In onegroup the amount of $1.5 \mathrm{wt} \%$ of $\mathrm{TiB}_{2}$ was added to evaluate the effect of reinforcement on the mechanical properties of produced foams (A15C45 sample) and the unreinforced sample (AC45) also prepared .In another group the age hardening treatment was performed on the unreinforced sample to investigate the related microstructural and mechanical behavior of cellular structure (HAC45 sample). $\mathrm{TiH}_{2}$ used as the foaming agent with $1 \mathrm{wt} \%$ in both groups. The prepared precursors were cold compacted under 75 bar pressure to produce cylindrical samples with $20 \mathrm{~mm}$ diameter and height. Foaming step was performed identically for both samples at $7000 \mathrm{c}$ at muffle furnace for 5 minutes. The samples of group 2 were heat treated and for this purpose heated to 5150 c for 14 hours and then cooled at cold water to obtain the saturated solid solution. Finally ageing treatment was performed at $1550 \mathrm{C}$ for 3 hours. The density of foams was calculated by dividing the mass of the samples to their volume. Uniaxial compression tests were performed on closed cell foam samples with $1 \mathrm{~mm} / \mathrm{min}$ speed to analysis the mechanical properties and energy absorption of porous structures was calculated according to the Eq.1. Where $\mathrm{W}$ is the absorbed energy, $\sigma$ is the stress and $\varepsilon \mathrm{D}$ is the densification strain that obtained from compressive stress strain curves.

$\mathrm{W}=\int_{0}^{\varepsilon D} \sigma d \varepsilon($ Eq.1)

Field Emission Scanning Electron Microscope used to study the microstructure and phase distributions within the matrix.

\section{Results and Discussion}

Fig. 1 shows the typical pore structure of the produced $\mathrm{Al}-4.5 \mathrm{wt} \% \mathrm{Cu}$ foam. Addition of $1.5 \mathrm{wt} \%$ of TiB2 altered the pore morphology from elliptical to near round shape. It seems that TiB2 particles acted as barriers during pore formation in the foaming step, but as it can be seen, the near round shape pores were not existed in all parts of the sample and in both cases, some immature pores are visible. The density of AC45 and A15C45 samples calculated 0.623 and 0.728 g.cm-3 respectively. It means that the TiB2 addition to the precursor increased the density of the porous structure about $17 \%$. It seems the reinforced particles did not distribute well within the matrix.The density of HAC45 sample was similar to AC45 one. In Fig.2a the compressive stress-strain curves of samples are shown. Similar to all of the porous metals, the compressive curves of the samples in this study exhibit three distinct regions (i) linear elastic, (ii) plateau and (iii) densification regions [2].

A comparison between the compressive stress strain curves o AC45 and A15C45 reveals that in the initial stages of the compression, the A15C45 exhibits lower level of stress and from strain of 0.2 it will be deformed at a relative higher stress in comparison with AC45 sample. This fact might be 
related to existence of ceramic reinforcement particles that enhanced the matrix hardness. As it can be concluded the effect of TiB2 reinforcement particles are not considerably high to increase the mechanical properties of the closed cell structure and only in the small strain rate range from 0.2 to about 0.4 the role of TiB2 particles can be detected. A comparison among the heat treated closed cell aluminum foam that has not been reinforce with TiB2 particles and two other produced foams reveal that the mechanical properties of the cellular structures increased in a good manner and throughout the compressive loads the HAC45 sample presents the higher stress level.In order to compare the energy absorption of the aluminum foam structures in Fig.2b the energy absorption of each sample has been depicted. According to the obtained results it is interesting to note that the heat treated aluminum foam reveal the highest energy absorptionat all of the strains compared with reinforced and non reinforced specimens. The differences among samples conclude that the effect of reinforcement addition on the energy absorption of AC45 is negligible in comparison with the age hardening treatment. This behavior attributed to the microstructure of the cellular structures that are demonstrated in Fig3a. As it can be seen from the SEM images and EDS mapping, the TiB2particles distributed heterogeneously throughout the structure and have not wetted appropriately by the aluminum matrix. In some regions, the agglomeration of these particles is also visible .In fact, the TiB2 particles in some parts of the structure act like stress concentration points and have not enhanced the energy absorption of porous structures ideally. On the other hand, the aging heat treatment of $\mathrm{Al}-4.5 \mathrm{wt} \% \mathrm{Cu}$ resulted in the in situ formation of phases like $\mathrm{Al} 2 \mathrm{Cu}$ within the aluminum matrix homogeneously [5]. In Fig 3b it is obvious that the obtained copper containing phases after heat treatment are fine in the spherical shape and obviously smaller than reinforced particles that covered the total surface of the cellular structure well. The size of these precipitates is smaller than TiB2 ceramic particles and their distance is very close in the structure. These in situ phases will act as the barrier against dislocations movement during compression and improve the mechanical properties of the cellular structures much more than TiB2 particles.

\section{Conclusion}

1. TiB2 reinforced and non reinforced Closed cell aluminum foams produced via powder metallurgy route.

2. TiB2 reinforcement due to heterogeneous distribution within the matrix did not enhance the mechanical properties of the closed cell aluminum foam in comparison with non reinforced specimen.

3. Heat treatment of the closed cell aluminum foams resulted in the distribution of fine intermetallic particles throughout the matrix homogeneously and enhanced mechanical properties and energy absorption of the cellular structure remarkably.

4. Heat treatment of $\mathrm{Al}-\mathrm{Cu}$ alloy foams instead of reinforcing with external ceramic additives produces stronger aluminum foams.

\section{References}

[1] J. Banhart, Proc. Mater. Sci. 46 (2001) 559-563.

[2] I. Duarte, E. Ventura, Susana Olhero,José MF Ferreira, Matter Lett. 160 (2015) 162-166. 
[3] W. Hall, M. Guden, C. Yu, Scr. Mater. 43 (2000) 515-521.

[4] U. AthulAtturan, S. H. Nandam, B.S. Murty, S. Sankaran, Mater Design.101 (2016) 245-253.

[5] I Fadhlina Mohamed, Y. Yonenaga, S. Lee, K. Edalati, Z. Horita, Mat SciEng A-Struct. 627 (2015) 111-118.

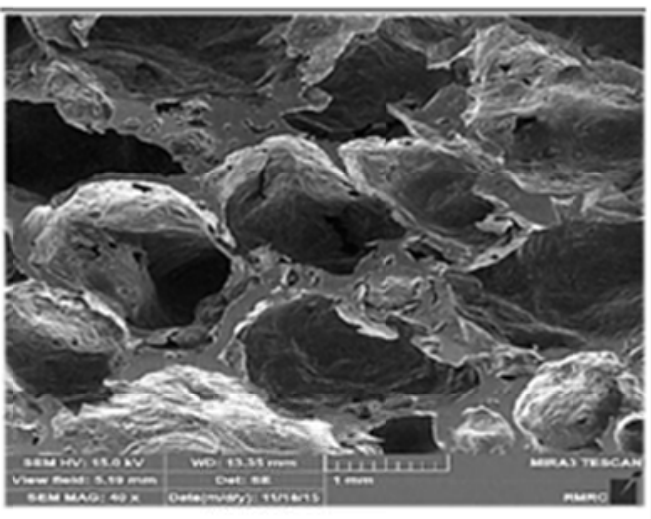

(a)

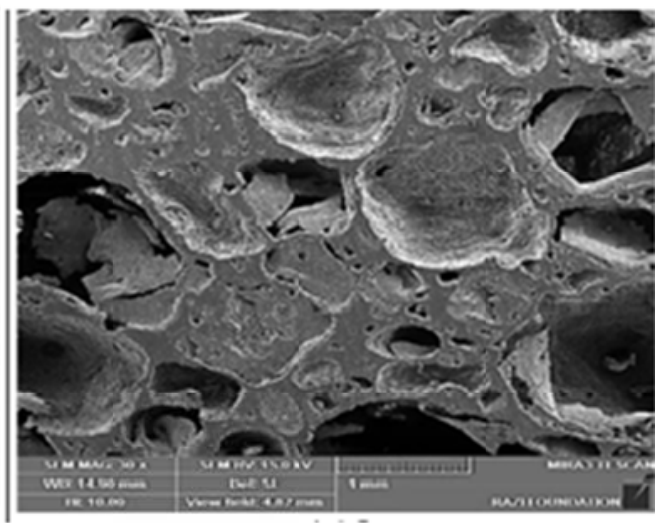

(b)

Fig.1 SEM image of the cellular structures of (a) AC45 and (b) A15C45 aluminum foams

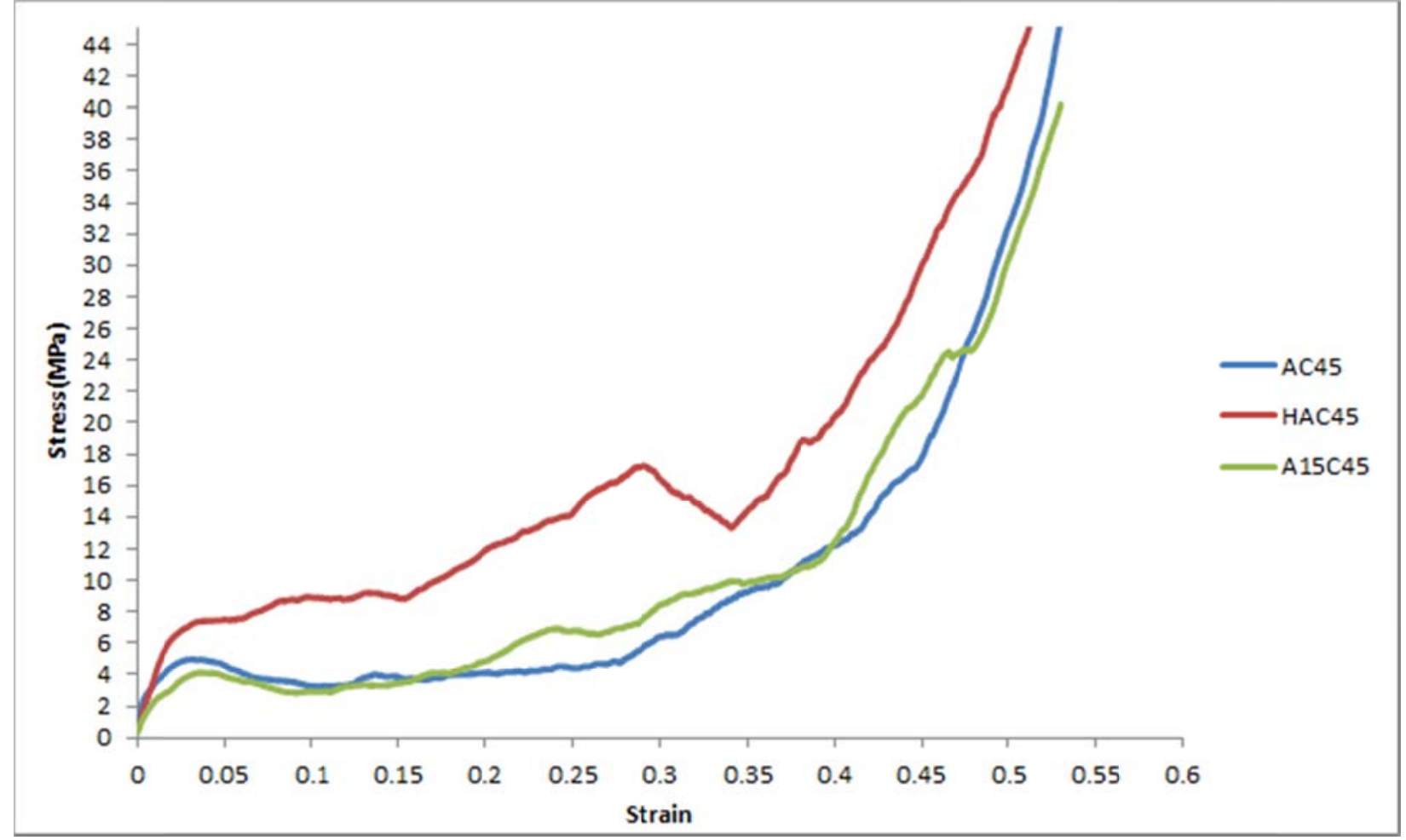

Fig2.a. Compressive Stress-Strain curves of Aluminum foams 


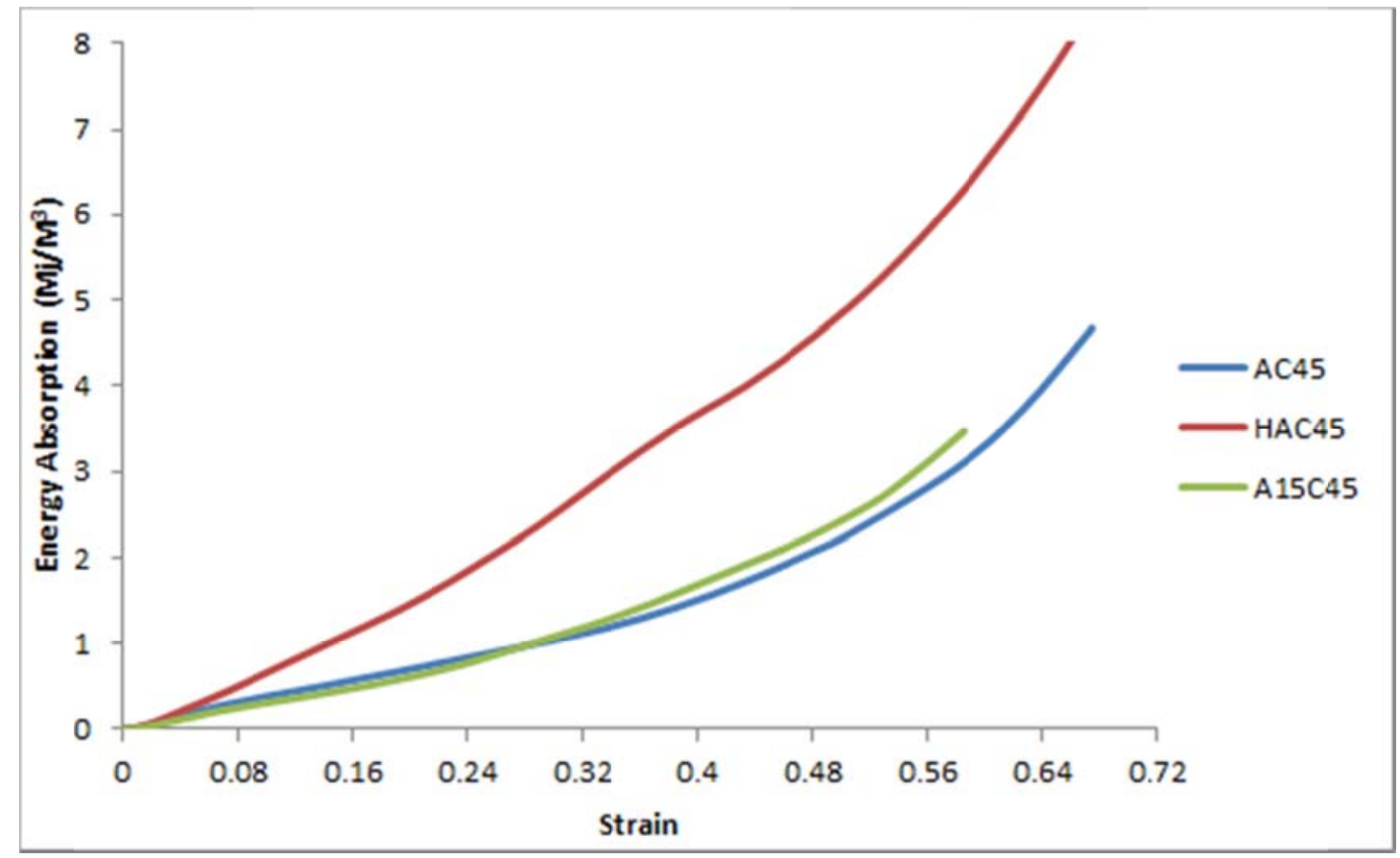

Fig.2.b. Energy absorption- strain curves of Aluminum foams

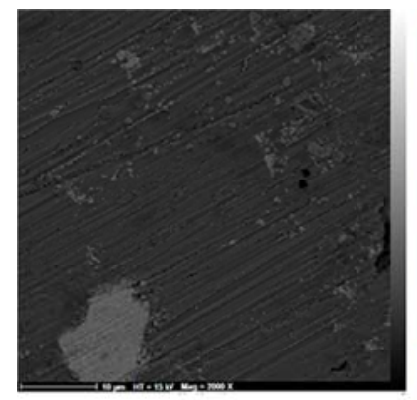

Cell wall matrix

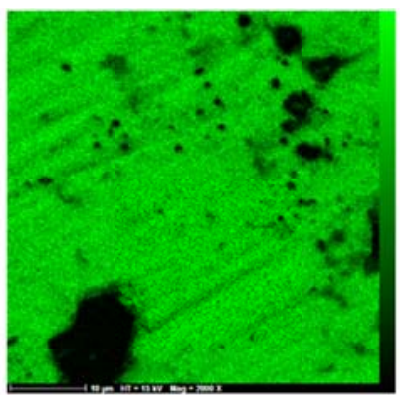

Aluminum map

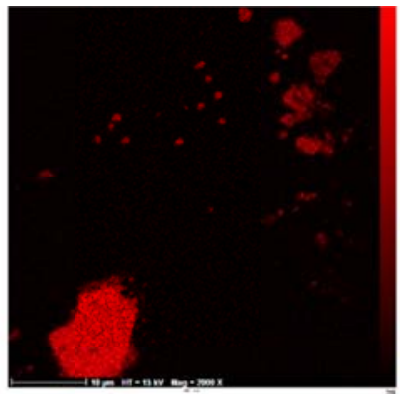

Titanium map

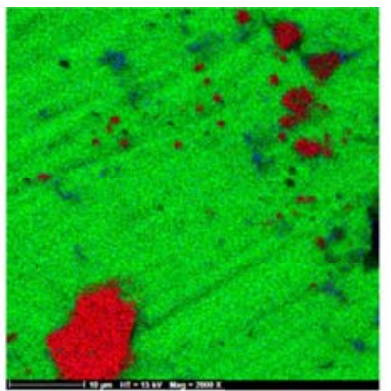

Aluminum-Titanium-Copper map

Fig.3.a SEM image and EDS mapping of A15C45

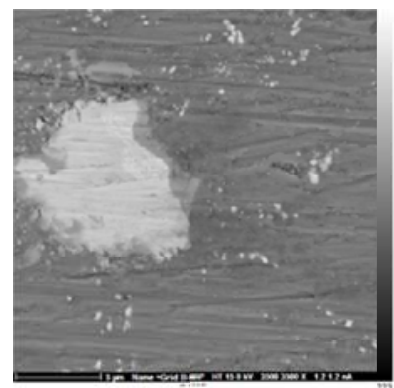

Cell Wall matrix

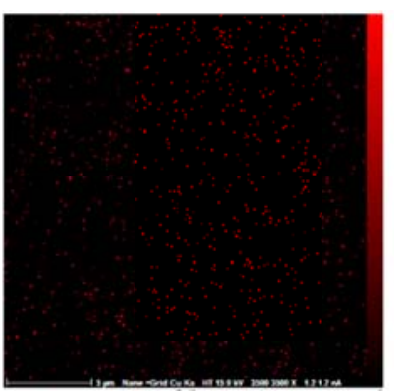

Copper map

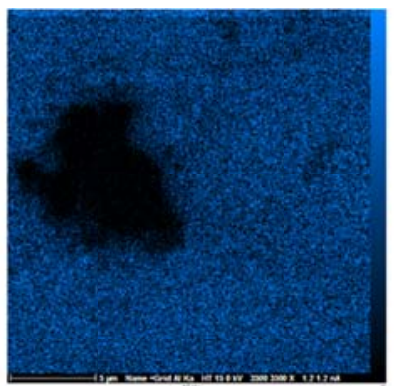

Aluminum map

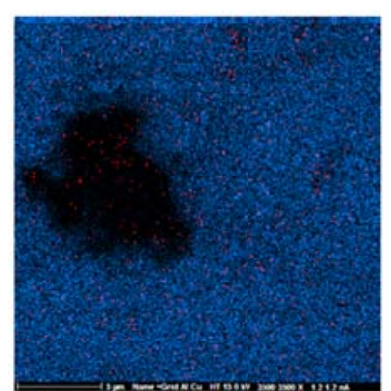

Aluminum-Copper map

Fig.3.b. SEM image and EDS mapping of HAC45 